\title{
UNIFAC Model for Liquid-Liquid Phase Equilibrium of Penicillin G and 6-APA System
}

\author{
Lienda Aliwarga*, Herri Susanto, Reynard Reynard, Agnes Veronica Victoria \\ Chemical Engineering Department, Bandung Institute of Technology \\ *Corresponding author: lienda@che.itb.ac.id
}

Received: November 2018; Revision: January 2019; Accepted: October 2019; Available online: November 2019

\begin{abstract}
This study investigated the effect of $\mathrm{pH}$ and type of solvent on liquid-liquid phase equilibrium in the system of pure penicillin $\mathrm{G}$ and mixed penicillin $\mathrm{G}$ with 6-APA. Penicillin $\mathrm{G}$ extraction was carried out in a $\mathrm{pH}$ range of 2.0-5.0 at $4{ }^{\circ} \mathrm{C}$ using several types of solvents. The liquid-liquid phase equilibrium mathematical model was prepared by assuming that a single stage of thermodynamic equilibrium occurs in a batch process of liquid-liquid extraction. The coefficient of activity was calculated by the UNIFAC method. From the experiment, it was found that the extraction process of penicillin $\mathrm{G}$ was strongly influenced by $\mathrm{pH}$ of the solution. The highest yield of extraction was achieved with different solvents in the two types of solution. For pure penicillin G system, the highest yield was obtained in n-butyl acetate solvent $(95.51 \%)$ while for penicillin G mixtured with 6-APA, it was obtained in methyl iso-butyl ketone solvent (92.6\%). The UNIFAC model has been tested against five threecomponent liquid-liquid phase equilibrium systems at $\mathrm{pH} 2.0$ and 2.5. It was able to estimate the concentration of penicillin $\mathrm{G}$ in the organic phase with a relatively average error between experiment and calculation of $8.32 \%$.
\end{abstract}

Keywords: Extraction, penicillin G, 6-APA, UNIFAC.

DOI: $10.15408 / j k v \cdot v 5 i 2.9869$

\section{INTRODUCTION}

The use of semi-synthetic penicillin as a natural penicillin derivative product is now increasingly widespread due to the nature of pathogenic microorganisms that are starting to be resistant to natural penicillin. The advantage of semi-synthetic penicillin is that it is resistant to beta-lactamase, broad-spectrum, and stable in acidic conditions (Singh and Goyal, 2014). This component is produced from the hydrolysis of penicillin $\mathrm{G}$ and $\mathrm{V}$ using the enzyme penicillin acylase or from a chemical reaction (Dhal, 2018; Haagensen, 2018; Sheldon and van Pelt, 2013; Szewczuk, 2018). Commercially, semi-synthetic penicillin is produced from 6-aminopenisilic acid (6-APA) through an enzymatic equilibrium reaction with penicillin acylase which yields in a mixture of 6-APA components, penicillin G, and phenylacetic acid (PAA) (Carleysmith and Lilly, 2018; Deo and Gaucher, 2018; Haagensen, 2018; Harvey, 2018; Park, 2018; Warburton, 2018). Purification of 6-APA resulting from enzymatic conversion from penicillin $G$ is carried out by extracting penicillin $\mathrm{G}$ which is not converted at low $\mathrm{pH}$. 6-APA in the phase of raffinate is concentrated and followed by crystallization in the isoelectric $\mathrm{pH}$ region (Deo and Gaucher, 2018; Haagensen, 2018; Karlsen and Villadsen, 2018). Separation of penicillin $G$ with liquidliquid extraction is conducted by utilizing the solubility difference of penicillin $G$ in the liquid phase and in the organic phase. Previously, the effect of $\mathrm{pH}$ and type of solvent on the solubility of pure penicillin $\mathrm{G}$ at $25{ }^{\circ} \mathrm{C}$ has been studied (Reschke and Schügerl, 1984a).

The thermodynamic model is assumed for one stage of equilibrium in liquid-liquid extraction of penicillin $G$ in batches and is arranged to obtain operating conditions and types of solvents suitable for the extraction of penicillin $G$ and a mixture of penicillin $G$ with 6-APA. The liquid-liquid phase equilibrium is expressed in terms of the similarity of the activity coefficients in both phases. The activity coefficient is a quantity that cannot be 
measured directly but can only be calculated, for example by using the Gibbs excess function of indexed Margules 2 (1895), Van Laar (1910), Felich-Kister (1948), and Black (1999) or by composition models Locals from Wilson (1964), NRTL (Non Random-Two Liquid) from Renon (1966) and UNIFAC (UNIquac Functional group Activity Coefficient) from Fredenslund (1975) (Sørensen, Magnussen, Rasmussen, and Fredenslund, 1979). The UNIFAC method has advantages in terms of the ability to determine the activity coefficient of a mixture without using experimental data. This method only requires three group parameters that form the components in the mixture, namely relative volume $\left(\mathrm{R}_{\mathrm{k}}\right)$, relative surface area $\left(\mathrm{Q}_{\mathrm{k}}\right)$, and interaction parameters $\left(\mathrm{a}_{\mathrm{mn}}\right)$ of each functional group (Sørensen et al., 1979).

This study examined the effect of $\mathrm{pH}$ and type of solvent on the liquid-liquid phase equilibrium in the penicillin $G$ system and the mixture of penicillin $G$ with 6-APA. The purpose of this study was to investigate the effect of $\mathrm{pH}$ and type of solvent on the distribution of penicillin G and 6-APA in the organic phase and the aquatic phase, determine the parameters of the UNIFAC ternary system interaction parameters (penicillin G-organic solvents and water) under certain $\mathrm{pH}$ conditions, and estimate concentration penicillin $G$ in both phases under equilibrium conditions through the model.

\section{MATERIALS AND METHODS Extraction of Penicillin G and 6-APA}

Extraction was carried out in a $100 \mathrm{~mL}$ separating funnel at $4{ }^{\circ} \mathrm{C}$. Before the extraction process was carried out, all materials and tools used were first cooled in a $4{ }^{\circ} \mathrm{C}$ temperature room. Penicillin $\mathrm{G}$ and 6-APA solutions were prepared by dissolving the material in a buffer solution at a certain $\mathrm{pH}$. This solution was extracted using organic solvents with equal volume ratio of the aquatic phase and organic phase. Stirring was done manually with a predetermined time. After the two phases separate, the concentration of penicillin $\mathrm{G}$ in the aquatic phase was measured by HPLC and the $\mathrm{pH}$ of the solution was measured by a $\mathrm{pH}$ meter. The distribution coefficient (D) was determined by using equation (1).

$D=\frac{[H P]_{\text {org }}}{[H P]_{r a f}}=\frac{C_{o}-C_{a}}{C_{a}}$ where $\mathrm{C}_{\mathrm{o}}$ is the initial penicillin $\mathrm{G}$ concentration in the aquatic phase and $\mathrm{C}_{\mathrm{a}}$ is penicillin $G$ concentration in the raffinate phase. The extraction percentage was calculated by equation (2)

$\% \mathrm{E}=\frac{[H P]_{\text {org }}}{[H P]_{\text {awal }}} \times 100 \%=\frac{C_{o}-C_{a}}{C_{o}} \times 100 \%$

The extraction of penicillin $\mathrm{G}$ from the the mixture of Penicillin G/6-APA was carried out the same as the extraction process on pure penicillin $\mathrm{G}$. In pure penicillin $\mathrm{G}$ extraction, a buffer solution of $\mathrm{pH} 2$ from a mixture of $\mathrm{HCl}$ and $\mathrm{KCl} ; \mathrm{pH} \mathrm{3,4}$, and 5 of a mixture of citric acid and disodium hydrogen phosphate were used. Meanwhile, for a mixture of penicillin $G$ with 6-APA, the citrate-phosphate buffer solution cannot be used because the peak of the chromatogram produced by 6-APA coincides with the peak of the glycine and $\mathrm{HCl}$ mixture buffer solution ( $\mathrm{pH} 3$ ) and $\mathrm{Na}$-acetic acid-acetic acid for $\mathrm{pH} 4$ and 5 .

\section{Determination of Partition Coefficient (Kd) and pKa}

Based on the distribution coefficient obtained form experimental results at various $\mathrm{pH}$ for each solvent, the value of $\mathrm{pKa}$ penicillin $\mathrm{G}$ was calculated by equation (3) using a correction factor at the initial $\mathrm{pKa}$ value of 2.75. The pKa value was determined by the Simplex method using the objective function of the difference between the least squares between the coefficients of the calculated distribution and the experimental data. The partition coefficient for each solvent was alculated by equation (3) using the pKa value of the results of optimization.

$\mathrm{D}=\frac{K_{d}}{1+10^{(p H-p K a)}}$

\section{Analysis Method}

The analysis of penicillin $G$ content was carried out with a Shimadzu HPLC type CR4A device using a column made of stainless steel with a diameter of $4.6 \mathrm{~mm}$ and a length of $25 \mathrm{~cm}$ with a stationary phase C-18. HPLC operating conditions are shown in Table 1.

Chromatographic data analysis was done qualitatively based on the suitability of retention time between samples and standard components. Meanwhile, quantitative analysis was carried out based on the peak chromatogram area obtained from the 
integrator by calibration outside the standard penicillin $\mathrm{G}$ peak.

Table 1. Operation conditions for HPLC

\begin{tabular}{ll}
\hline \multicolumn{1}{c}{ Parameters } & \multicolumn{1}{c}{ Value } \\
\hline $\begin{array}{l}\text { Column } \\
\text { temperature }\end{array}$ & $33^{\circ} \mathrm{C}$ \\
$\begin{array}{l}\text { Detector } \\
\text { Sample volume }\end{array}$ & $\mathrm{UV}(\lambda=220 \mathrm{~nm})$ \\
Mobile phase & $\begin{array}{l}\text { Acetonitrile: phosphate } \\
\text { buffer }(0.025 \mathrm{M}) \mathrm{pH} 7=2: 8\end{array}$ \\
$\begin{array}{l}\text { Flowrate of the } \\
\text { mobile phase }\end{array}$ & $1 \mathrm{~mL} / \mathrm{min}$ \\
\hline
\end{tabular}

\section{RESULTS AND DISCUSSION Determination of Stirring Time}

Stirring time is the minimum time required to obtain the phase equilibrium, which is indicated by the concentration of penicillin G. The residual in the raffinate phase has not changed with the variation of the stirring time. Based on observations, the stirring time does not significantly affect the extraction percentage (Figure 1).

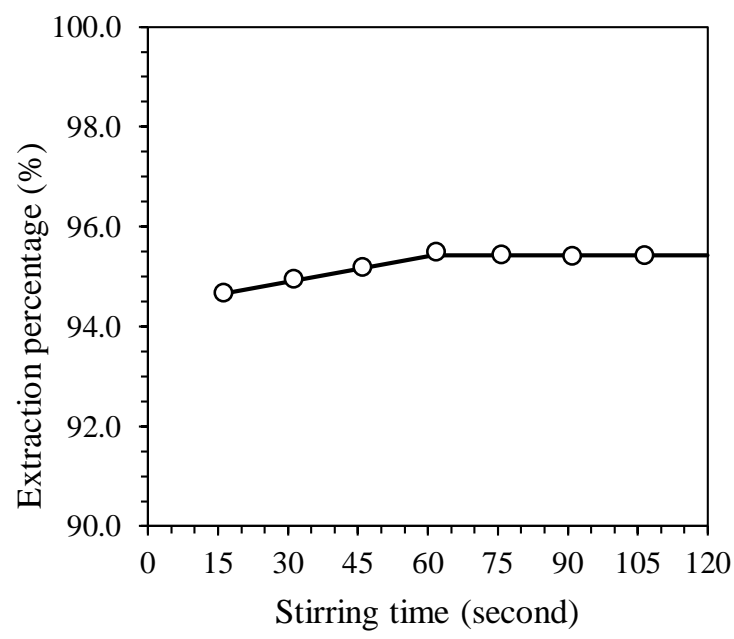

Figure 1. The extraction percentage at a various stirring time

The extraction percentage price is in the range of $94.5-95.5 \%$. When the stirring time is less than 60 seconds, the extraction percentage tends to increase. This might be due to the contact between the organic phase and the aquatic phase is still not perfect and the extraction conditions have not reached equilibrium. The residual concentration of penicillin $G$ in the raffinate phase is relatively constant during the stirring time of 60 seconds. After 60 seconds, the addition of the stirring time did not significantly affect the concentration of penicillin $G$ in the raffinate phase and the conditions had reached equilibrium. Therefore, the stirring time used in this study was 60 seconds ( 1 minute).

\section{Partition Coefficient and Extraction Percentage of Pure Penicillin G System}

The partitioning coefficient of penicillin $G$ in various solvents shown in Table 2 is obtained from the optimum pKa which is the result of optimization of the difference in the smallest square between the distribution coefficient of the experimental data with the distribution coefficient of the calculated results. The experimental results show that the largest partition coefficient of penicillin $G$ was obtained in the solvent n-butyl acetate (21.47) and the lowest partition coefficient in chloroform (5.885).

Table 2. Partition coefficient of penicillin $\mathrm{G}$ in pure penicillin $\mathrm{G}$ system $(\mathrm{pKa}=3.015)$

\begin{tabular}{ccc}
\hline Solvent & Kd & $\begin{array}{c}\text { Kd (Reschke } \\
\text { \& Schugerl, } \\
\mathbf{1 9 8 4 b})\end{array}$ \\
\hline N-butyl acetate & 21.47 & 48 \\
isobutyl acetate & 13.62 & 37 \\
Isoamyl acetate & 12.05 & 22 \\
Methyl isobutyl & 8.017 & - \\
$\quad$ ketone & 5.885 & 12.5 \\
Chloroform & \\
\hline
\end{tabular}

A noticeable difference between the experimental results and the partition coefficient data were obtained by (Reschke and Schügerl, 1984b). This may be influenced by a decrease in temperature, causing the penicillin $\mathrm{G}$ solubility to get smaller. In the literature, experiments were carried out at $8{ }^{\circ} \mathrm{C}$, whereas in this study, $4{ }^{\circ} \mathrm{C}$ was chosen. This was supported by (Jing, 2010) that reported data on the solubility of penicillin sulfoxide in various solvents with the temperature range of 273.15$298.55 \mathrm{~K}$, the solubility decreased in a lower temperature due to the differences in solvent polarity, intermolecular interactions, hydrogen bonds, and others. Furthermore, the number of solvent mole fractions can also determined the solubility of penicillin, where the higher the mole fraction of water, the solubility of penicillin $\mathrm{G}$ in the aquatic phase will increase 
because of its ionic and polar property. If the solubility of penicillin $G$ increases in the aquatic phase, while in the raffinate phase does not change significantly, the partitions coefficient will be even greater. This is consistent with the thermodynamic data obtained for penicillin $\mathrm{V}$ potassium (PVK) in the ethanol-water system and the 1-butyl alcohol-water system at 278.15-313.15 K using the correlation of Van not Hoff and modified Apelblat (Wei, 2015).

The percentage of extraction of penicillin $\mathrm{G}$ at various $\mathrm{pH}$ from calculations using partition coefficient and $\mathrm{pKa}$ obtained from the optimization is shown in Figure 2. The results show that at $\mathrm{pH}$ around 2 , the extraction percentage is not so affected by slight changes in $\mathrm{pH}$ (tends to remain) but at $\mathrm{pH}$ above 3, there was a sharp decrease in extraction due to changes in $\mathrm{pH}$. For example, for n-butyl acetate solvents at $\mathrm{pH} 4$ and 5 , the percentage of extractions was $66.83 \%$ and $18.03 \%$, respectively. Observation of the five types of solvents used showed that the largest percentage of extraction was given by n-butyl acetate, iso-butyl acetate, isoamyl acetate, methyl iso-butyl ketone, and chloroform.

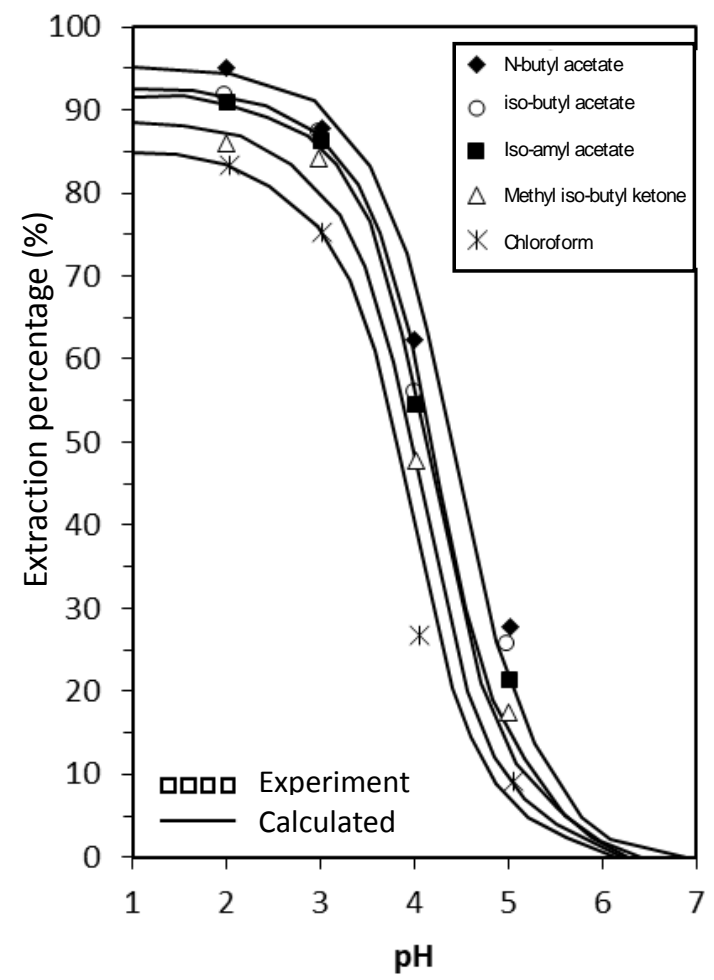

Figure 2. Extraction of penicillin $\mathrm{G}$ at various $\mathrm{pH}$

\section{Partition Coefficient and Extraction Percentage of Penicillin G Mixed Systems with 6-APA}

The result shows that 6-APA is difficult to extract from the mixture by organic solvents. This phenomenon may be attributed to the fact that 6-APA is an amphoteric component (acidic and basic) with $\mathrm{pKa}_{1}=2.3$ $(\mathrm{COOH})$ and $\mathrm{pKa}_{2}=4.9\left(\mathrm{NH}_{3}+\right)$. At low $\mathrm{pH}$ (below $\mathrm{pKa}_{1}$ ), 6-APA is more dominant in acidic form and more soluble in water. If the $\mathrm{pH}$ of the solution is greater than $\mathrm{pKa}_{2}, 6-\mathrm{APA}$ is dominated by anionic form. Meanwhile, if the $\mathrm{pH}$ of the solution is between $\mathrm{pKa}_{1}$ and $\mathrm{pKa}_{2}$, acids and bases are in the mixture in the solution. This condition is known as zwitterion.

The largest percentage of 6-APA extraction is given by chloroform solvents, while the smallest percentage is given by isobutyl acetate solvents, as shown in Figure 3. This may be due to the quite different chemical properties of each solvent. Because 6-APA is a nonpolar component, it is more soluble in nonpolar solvents. In addition, the dependence of the extraction percentage of 6-APA on the $\mathrm{pH}$ for each solvent is quite diverse but generally shows that at $\mathrm{pH}$ in the isoelectrocuted area ( $\mathrm{pI}$ 6-APA $=4.3$ ), the percentage of 6-APA extraction is in optimum condition. In the $\mathrm{pI}$ region, 6-APA is dominant in the form of neutral components so that it is easily extracted into organic solvents. Meanwhile, at $\mathrm{pH}$ outside the area, 6-APA is dominant in the form of charged ions (Su et al., 2016).

In the mixture of penicillin $\mathrm{G}$ with 6APA, the percentage of penicillin $G$ extraction also changes when compared to the pure penicillin $G$ system. Based on the distribution coefficient data of the experimental and by using the $\mathrm{pKa}$ penicillin $\mathrm{G}$ price obtained from the extraction of pure penicillin $\mathrm{G}(\mathrm{pKa}=$ 3.015), the partition coefficient values are shown in Table 3.

Tabel 3. Penicillin G partition coefficient on penicillin $\mathrm{G} / 6$-APA systems $(\mathrm{pKa}=3.015)$

\begin{tabular}{lcc}
\hline \multicolumn{1}{c}{ Solvent } & Kd & $\mathbf{f}(\mathbf{x})$ residue \\
\hline N-butyl acetate & 10.91 & 1.294 \\
isobutyl acetate & 11.17 & 2.491 \\
Isoamyl acetate & 10.53 & 7.046 \\
Methyl isobutyl & 12.98 & 7.546 \\
ketone & 7.20 & 0.727 \\
Chloroform &
\end{tabular}



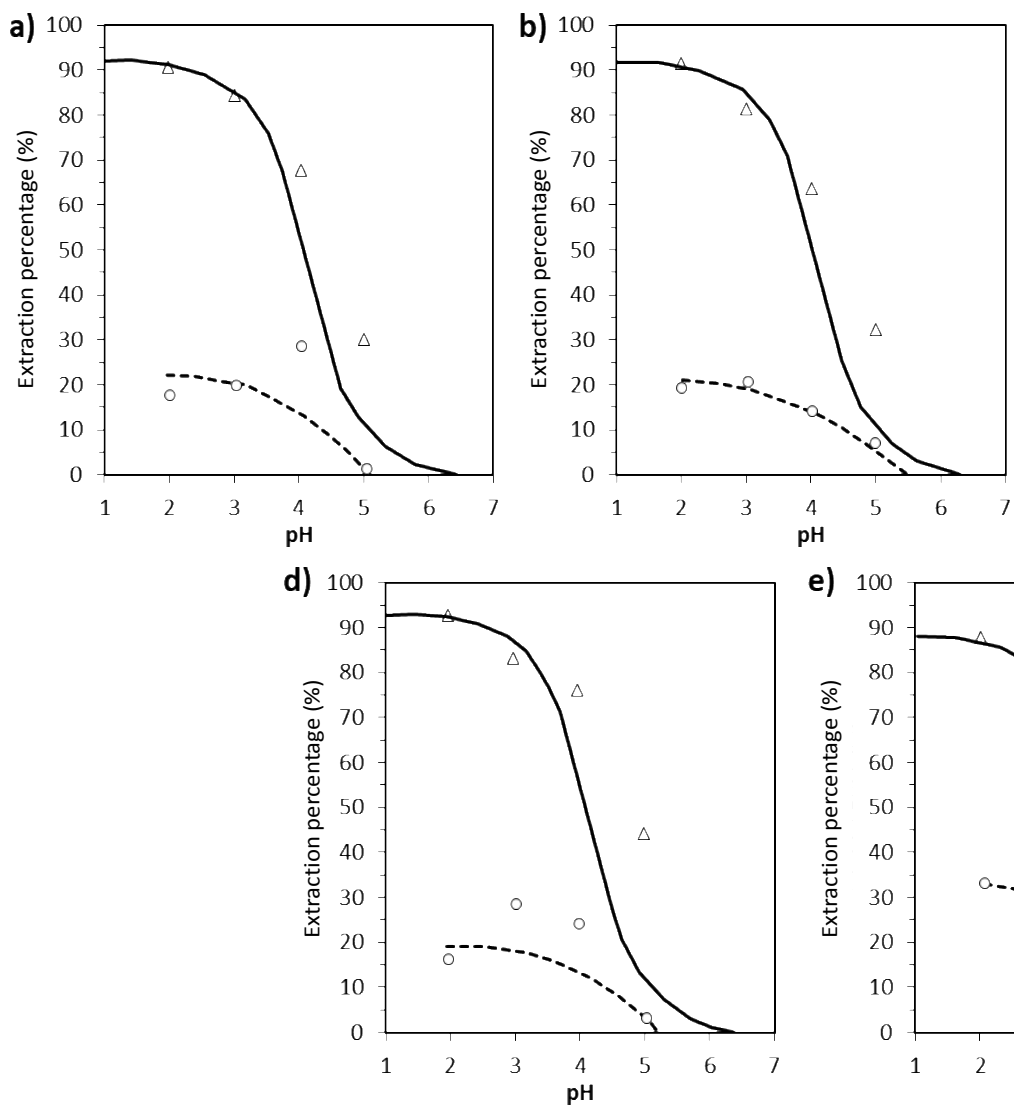
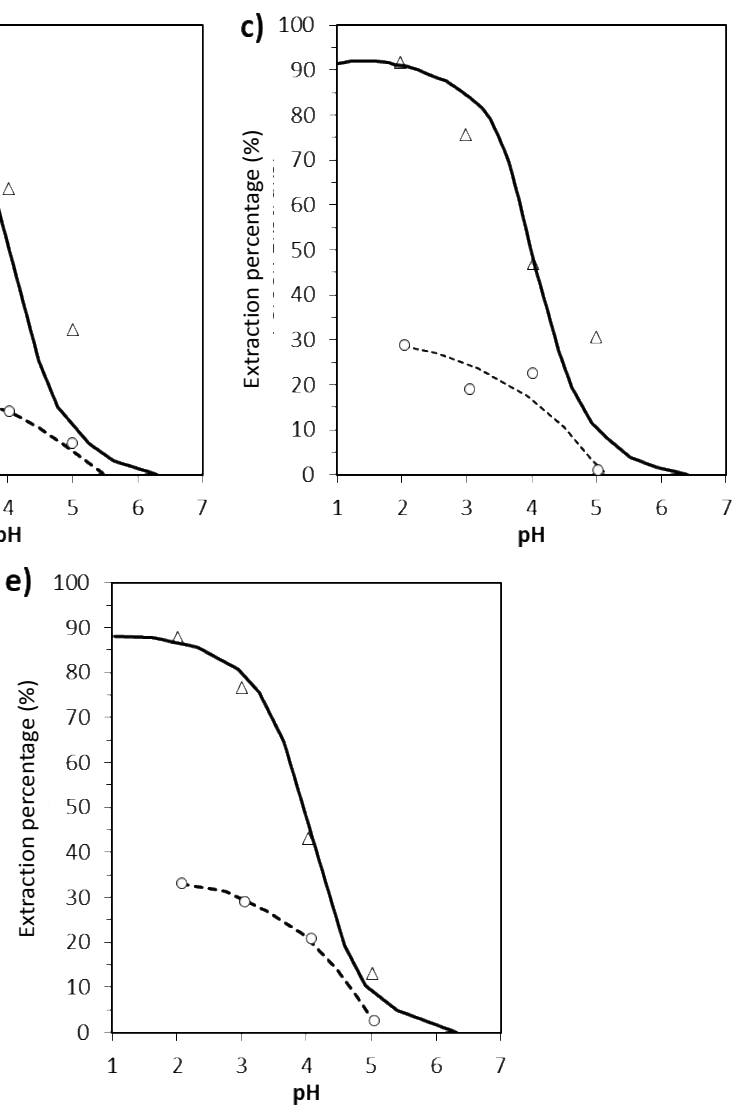

Figure 3. Extraction of penicillin $\mathrm{G}$ and 6 -APA at $4{ }^{\circ} \mathrm{C}$ with (a) n-butyl acetate, (b) i-butyl acetate, (c) n-amyl acetate, (d) m-i-b-ketone, and (e) chloroform.

The partitioning coefficient of penicillin $\mathrm{G}$ in penicillin G/6-APA systems has decreased when compared to the partition coefficient of the pure penicillin $G$ system, except for the methyl iso-butyl ketone and chloroform. This might be due to the influence of 6-APA which can increase the solubility of penicillin $G$ in solvents that have relatively smaller polarity.

Methyl iso-butyl ketone is a suitable solvent used to separate penicillin G/6-APA. As shown in Table 3, methyl iso-butyl ketone provides the greatest partition coefficient. At $\mathrm{pH} 2$, methyl iso-butyl ketone only produces an extraction percentage of less than $20 \%$ while the other solvents give an extraction percentage above $30 \%$. In contrast, methyl iso-butyl ketone gives the largest percentage of extraction $(92.21 \%)$ for penicillin G.

\section{Determination of Penicillin G Concentration in Equilibrium Conditions with the UNIFAC Model}

The relative volume $\left(R_{k}\right)$ and the relative surface area $\left(\mathrm{Q}_{\mathrm{k}}\right)$ of each functional group were calculated by equations (4) and (5). By using $V_{w k}$ and $A_{w k}$ data provided by Daubert (1985), values of $R_{k}$ and $Q_{k}$ were obtained and shown in Table 4.

Table 4. Volume and surface area of each component

\begin{tabular}{lll}
\hline Solvent & $\mathbf{R}_{\mathbf{k}}\left(\mathbf{c m}^{\mathbf{3}} \mathbf{m o l}\right)$ & $\mathbf{Q}_{\mathbf{k}}\left(\mathbf{c m}^{2} / \mathbf{m o l}\right)$ \\
\hline N-butyl acetate & 4.82 & 4.196 \\
isobutyl acetate & 4.82 & 4.192 \\
Isoamyl acetate & 5.4944 & 4.736 \\
Methyl isobutyl & 4.60 & 4.03 \\
ketone & & \\
Chloroform & 2.82 & 2.40 \\
Water & 0.92 & 1.40 \\
Penicillin G & 11.4739 & 8.476 \\
\hline
\end{tabular}

Refs. (Daubert \& Danner, 1985)

For the penicillin $\mathrm{G}$ component, the $\mathrm{R}_{\mathrm{k}}$ and $\mathrm{Q}_{\mathrm{k}}$ data are the sum-up of $\mathrm{R}_{\mathrm{k}}$ and $\mathrm{Q}_{\mathrm{k}}$ data from the constituent groups.

$R_{k}=V_{w k} / 15.17$ 
$Q_{k}=\frac{A_{w k}}{2.5 \times 10^{9}}$

where $V_{w k}$ is the volume of functional groups and $A_{w k}$ is the surface area of the functional groups.

Based on the concentration data under the equilibrium conditions of the experimental results and by using the objective function in equation (6), the results of the calculation of the interaction parameters at each $\mathrm{pH}$ were obtained as shown in Table 5 and Table 6.

$F(\tau)=\sum_{i}^{j} \sum_{i}^{i}\left[x_{i}^{I}-\widehat{x}_{i}^{I}\right]^{2}$

where $x_{i}^{I}$ is concentration of component $\mathrm{i}$ in phase I (experiment result), $\hat{x}_{i}^{I}$ is concentration of component $\mathrm{i}$ in phase I obtained from the calculation, and $\mathrm{j}$ is the number of data.

Parameter interactions with the remaining relatively small objective functions for the five liquid-liquid phase equilibrium of the ternary system, except for the waterchloroform-penicillin $\mathrm{G}$ system can be observed in Table 5 and Table 6. These tables show that the changes in $\mathrm{pH}$ conditions in the aquatic phase also results in the changes in the interaction parameter estimated on the same ternary system.

The relationship of calculated concentration (mole fraction) of penicillin $G$ with the concentration of penicillin $G$ in the feed is given in Figure 4 and Figure 5. These results show that the calculated values are in good agreement with experimental data, especially at low concentrations. Increasing the concentration of penicillin $\mathrm{G}$ in the feed causes the greater deviation between estimation and experimental results. This phenomenon may occur because the solubility of penicillin $G$ in the organic phase has exceeded the saturation limit at high penicillin $\mathrm{G}$ concentrations (above $10 \mathrm{mmol} / \mathrm{L}$ ). Thus, an increase in the concentration of penicillin $G$ in the feed does not affect the concentration of penicillin $G$ in the organic phase so that the value of the equilibrium constant decreases.

Table 5. Interaction parameters of the three-component liquid-liquid equilibrium system at pH 2 and $4{ }^{\circ} \mathrm{C}$

\begin{tabular}{cccccccccc}
\hline & Component & & \multicolumn{6}{c}{ Interaction parameter (K) } & \multicolumn{2}{c}{$\mathbf{F}(\mathbf{x})$} \\
$\mathbf{1}$ & $\mathbf{2}$ & $\mathbf{3}$ & $\mathbf{a}_{\mathbf{1 2}}$ & $\mathbf{a}_{\mathbf{1 3}}$ & $\mathbf{a}_{\mathbf{2 1}}$ & $\mathbf{a}_{\mathbf{2 3}}$ & $\mathbf{a}_{\mathbf{3 1}}$ & $\mathbf{a}_{\mathbf{3 2}}$ & residual \\
\hline \multirow{4}{*}{ Water } & N-butyl acetate & & 725.06 & - & 622.64 & - & 597.77 & -3.51 & 0.001136 \\
& & & & 751.89 & & 498.01 & & & \\
& isobutyl acetate & & 719.81 & - & 690.50 & - & 601.37 & 23.02 & 0.00398 \\
& & & & 555.91 & & 366.62 & & & \\
& Isoamyl acetate & Penicillin & 625.14 & - & 504.28 & - & 499.31 & 7.86 & 0.00387 \\
& Methyl isobutyl & $\mathrm{G}$ & & 614.26 & & 441.95 & & & \\
& ketone & & 762.10 & - & 699.25 & - & 729.44 & 146.6 & 0.00047 \\
& Chloroform & & & 939.43 & & 780.98 & & & \\
& & 696.66 & - & 776.33 & - & 499.64 & 4.03 & 5.966 \\
\hline
\end{tabular}

Table 6. Interaction parameters of the three-component liquid-liquid equilibrium system at $\mathrm{pH} 2$ and $4{ }^{\circ} \mathrm{C}$

\begin{tabular}{cccccccccc}
\hline & Component & & \multicolumn{6}{c}{ Interaction parameter $(\mathbf{K})$} & \multicolumn{2}{c}{$\mathbf{F}(\mathbf{x})$} \\
$\mathbf{1}$ & $\mathbf{2}$ & $\mathbf{3}$ & $\mathbf{a}_{\mathbf{1 2}}$ & $\mathbf{a}_{\mathbf{1 3}}$ & $\mathbf{a}_{\mathbf{2 1}}$ & $\mathbf{a}_{\mathbf{2 3}}$ & $\mathbf{a}_{\mathbf{3 1}}$ & $\mathbf{a}_{\mathbf{3 2}}$ & residual \\
\hline \multirow{4}{*}{ Water } & n-b asetat & & 720.40 & -539.70 & 695.37 & -374.43 & 592.70 & 3.12 & 0.00734 \\
& i-b-asetat & & 724.16 & -499.02 & 632.53 & -368.07 & 470.80 & 41.87 & 0.00259 \\
& i-a-asetat & Penicillin & 621.53 & -609.14 & 524.07 & -403.00 & 480.03 & -4.85 & 0.00295 \\
& n-i-b-keton & $\mathrm{G}$ & 762.20 & -922.86 & 704.21 & -652.08 & 693.91 & -13.7 & 0.000593 \\
& kloroform & & 696.66 & -842.67 & 776.33 & -560.53 & 499.64 & 4.03 & 5.966 \\
\hline
\end{tabular}



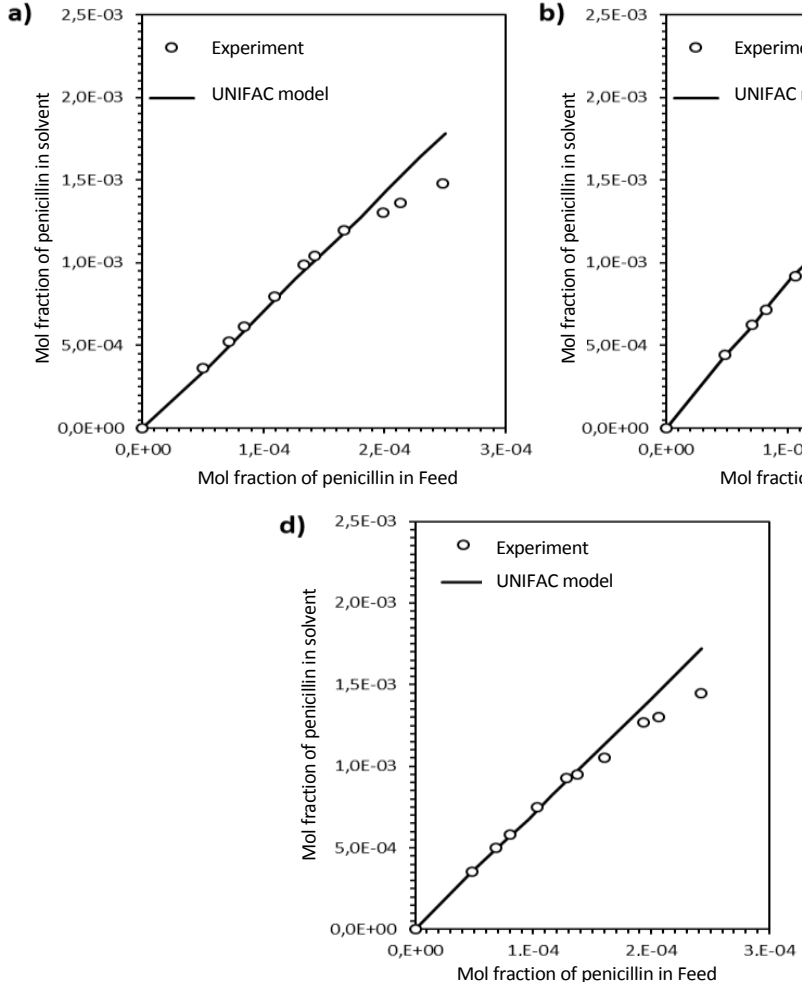
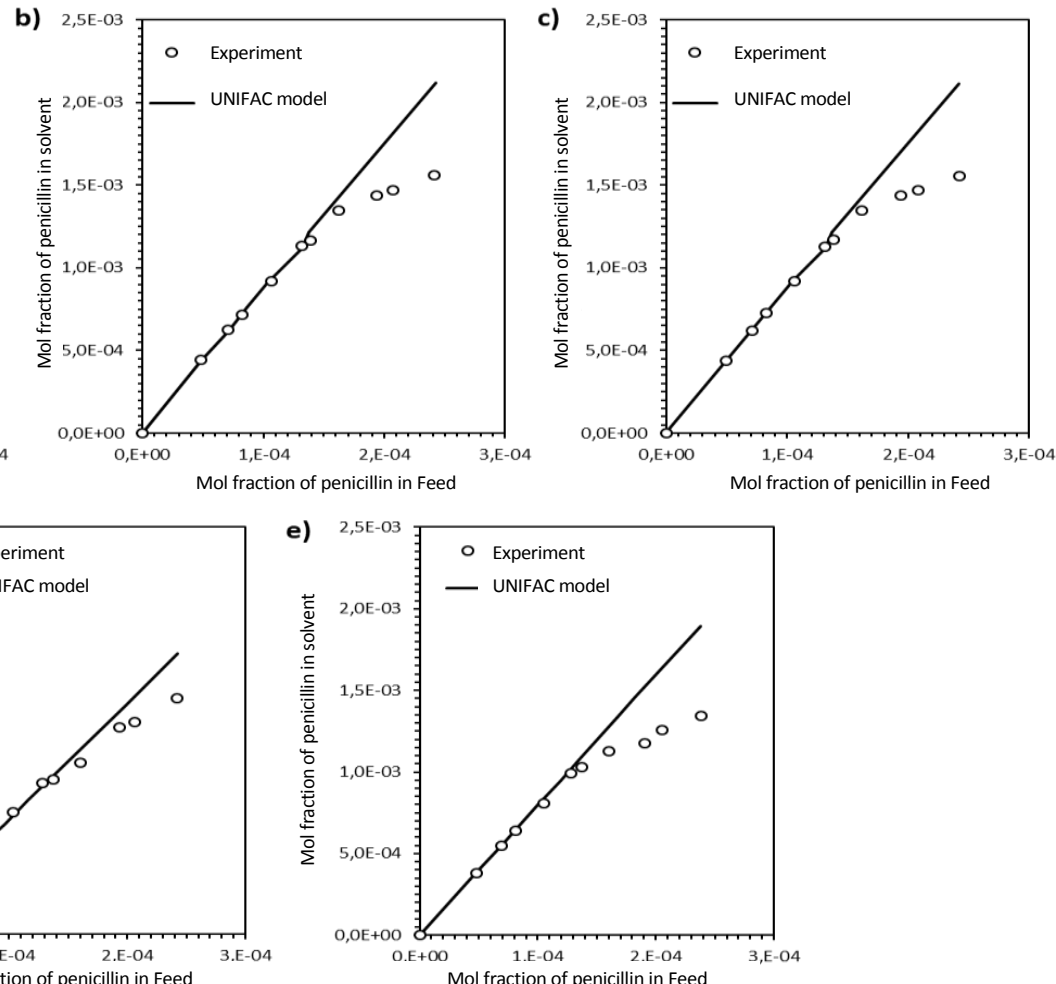

Figure 4. The equilibrium curve of penicillin $\mathrm{G}$ in (a) n-butyl acetate, (b) i-butyl acetate, (c) n-amyl acetate, (d) mib-ketone, and (e) chloroform, at $\mathrm{pH} 2.0$ and $4{ }^{\circ} \mathrm{C}$.
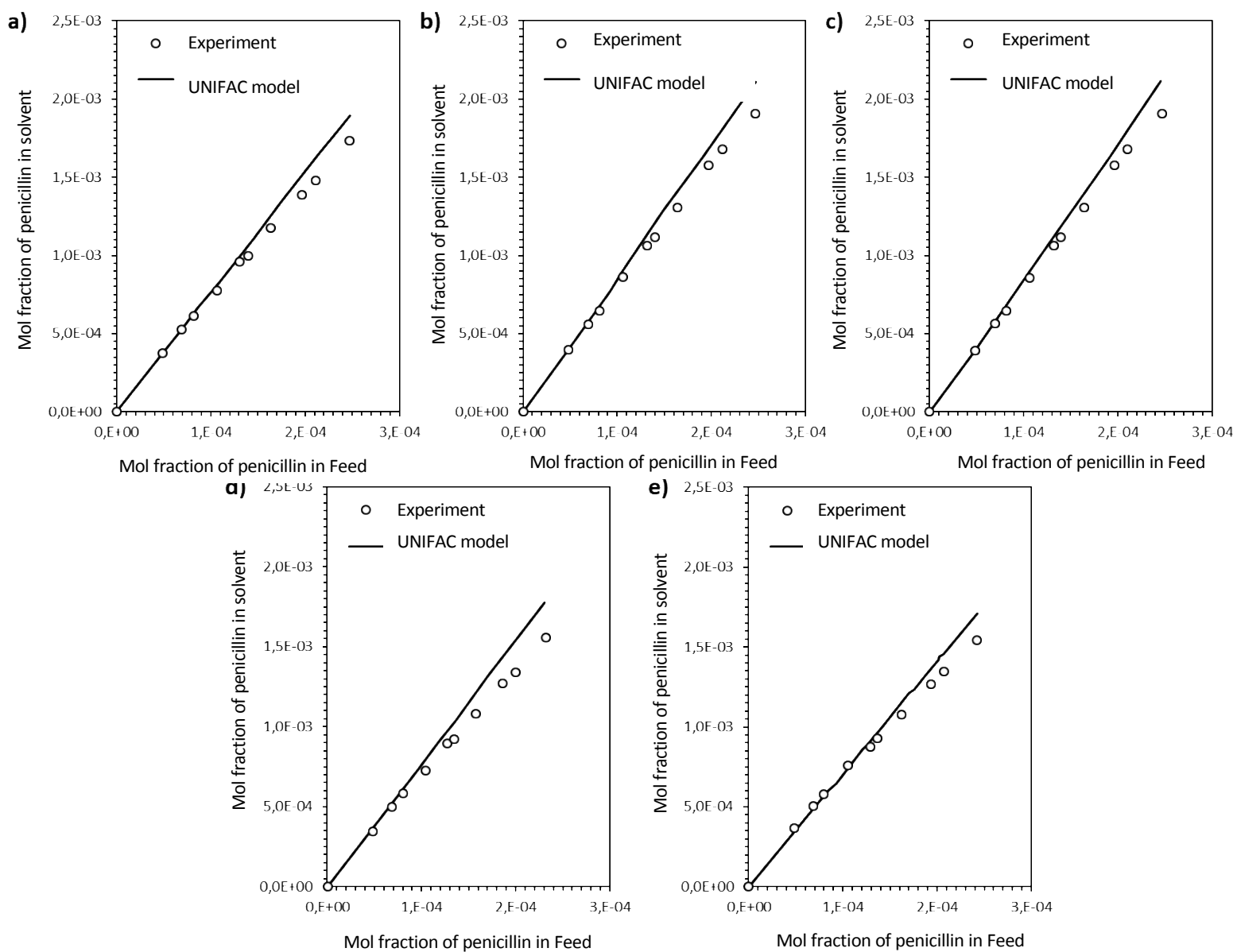

Figure 5. Penicillin G equilibrium curves in (a) n-butyl acetate, (b) i-butyl acetate, (c) n-amyl acetate, (d) mib ketone, and (e) chloroform, at $\mathrm{pH} 2.5$ and $4{ }^{\circ} \mathrm{C}$. 
Table 7. The relative error in determining the concentration of penicillin $G$ in the organic phase calculated by UNIFAC model and experimental data

\begin{tabular}{lcc}
\hline \multicolumn{1}{c}{ Solvent } & $\mathbf{R}_{\mathbf{k}}\left(\mathbf{c m}^{\mathbf{3}} \mathbf{m o l}\right)$ & $\mathbf{Q}_{\mathbf{k}}\left(\mathbf{c m}^{\mathbf{2}} / \mathbf{m o l}\right)$ \\
\hline Water - n-b-asetate - penicillin G & 2.0 & 6.156 \\
Water - n-b-asetate - penicillin G & 2.5 & 5.554 \\
Water - i-b-asetate - penicillin G & 2.0 & 12.198 \\
Water - i-b-asetate - penicillin G & 2.5 & 6.826 \\
Water - i-a-asetate - penicillin G & 2.0 & 9.536 \\
Water - i-a-asetate - penicillin G & 2.5 & 6.862 \\
Water - m-i-b-asetate - penicillin G & 2.0 & 6.058 \\
Water - m-i-b-asetate - penicillin G & 2.5 & 10.345 \\
Water - Chloroform - penicillin G & 2.0 & 13.783 \\
Water - Chloroform - penicillin G & 2.5 & 5.894 \\
\hline
\end{tabular}

Based on errors analysis, deviations between the calculation with experimental data are listed in Table 7. The results of calculations through the model give an average of $8.32 \%$. The largest deviation was obtained in the water system (1)-chloroform (2)-penicillin G (3) at $\mathrm{pH} 2$ with a relative error of $13.782 \%$. The smallest deviation was obtained in the water system (1)- n-butyl acetate (2)- penicillin G (3) at $\mathrm{pH} 2.5$ with a relative error of $5.554 \%$.

\section{CONCLUSION}

The percentage of extraction and distribution coefficient of penicillin $\mathrm{G}$ and 6APA in various solvents is influenced by the $\mathrm{pH}$ of the aquatic phase. The highest extraction percentage for pure penicillin $G$ system is obtained in the n-butyl acetate solvent (95.51\%) and for the mixture of penicillin $G$ and 6-APA obtained in the methyl iso-butyl ketone solvent $(92.6 \%)$. The best solvent for the separation of penicillin $\mathrm{G}$ from a penicillin G/6-APA mixture is methyl isobutyl ketone. Mathematical model of equilibrium of penicillin $\mathrm{G}$ in water and organic solvents is made to determine the activity coefficient using the UNIFAC method. This model is able to estimate penicillin $\mathrm{G}$ concentrations in the organic phase with an average relative error of $8.32 \%$.

\section{REFERENCES}

Carleysmith SW, Lilly MD. 2018. Deacylation of benzylpenicillin by immobilized penicillin acylase in a continuous four-stage stirredtank reactor. Biotechnology and Bioengineering. 21(6): 1057-1073. https://doi.org/10.1002/bit.260210610.
Daubert TE, Danner RP. 1985. Data Compilation Tables of Properties of Pure Compounds. New York.

Deo YM, Gaucher GM. 2018. Semicontinuous and continuous production of penicillin- $\mathrm{G}$ by Penicillium chrysogenum cells immobilized in $\kappa$-carrageenan beads. Biotechnology and Bioengineering. 26(3): 285-295.

https://doi.org/10.1002/bit.260260314.

Dhal PK, Babu GN, Sudhakaran S, Borkar PS. 2018. Immobilization of penicillin acylase by covalent linkage on vinyl copolymers containing epoxy groups. Die Makromolekulare Chemie, Rapid Communications. 6(2): 91-95. https://doi.org/10.1002/marc.1985.030060 208.

Haagensen P, Karlsen LG, Petersen J, Villadsen J. 2018. The kinetics of penicillin-V deacylation on an immobilized enzyme. Biotechnology and Bioengineering. 25(7): 1873-1895.

https://doi.org/10.1002/bit.260250715.

Harvey W, Blanch SD, Daniel I, CW. 2018. Book Review: Comprehensive Biotechnology. The Principles, Applications and Regulations of Biotechnology in Industry, Agriculture and Medicine. Editor-in-chief: M. Moo-Young. Angewandte Chemie International Edition in English. 26(6): 588. https://doi.org/10.1002/anie.198705881.

Jing D, Wang J, Wang Y. 2010. Solubility of penicillin sulfoxide in different solvents. Journal of Chemical and Engineering Data. $\quad 55(1)$ : 508-509. https://doi.org/10.1021/je900326e. 
Karlsen LG, Villadsen J. 2018. Optimization of a reactor assembly for the production of 6APA from penicillin-V. Biotechnology and Bioengineering. 26(12): 1485-1491. https://doi.org/10.1002/bit.260261213.

Park JM, Choi CY, Seong BL, Han MH. 2018. The production of 6-aminopenicillanic acid by a multistage tubular reactor packed with immobilized penicillin amidase. Biotechnology and Bioengineering. 24(7): 1623-1637.

https://doi.org/10.1002/bit.260240714.

Reschke M, Schügerl K. 1984a. Reactive extraction of penicillin I: Stability of penicillin $G$ in the presence of carriers and relationships for distribution coefficients and degrees. The Chemical Engineering Journal. 28(1): B1-B9. https://doi.org/https://doi.org/10.1016/030 0-9467(84)85015-7.

Reschke M, Schügerl K. 1984b. Reactive extraction of penicillin II: Distribution coefficients and degrees of extraction. The Chemical Engineering Journal. 28(1): B11-B20. https://doi.org/https://doi.org/10.1016/030 0-9467(84)85016-9.

Sheldon RA, Van Pelt S. 2013. Enzyme immobilisation in biocatalysis: why, what and how. Chem. Soc. Rev. 42: 6223-6235.

Singh V, Goyal SG. 2014. Penicillin G Acylase, a biocatalyst and its potential application. International Journal of Scientific \& Engineering Research. 5(5): 153-158.

Sørensen JM, Magnussen T, Rasmussen P, Fredenslund A. 1979. Liquid-liquid equilibrium data: Their retrieval, correlation and prediction Part I: Retrieval. Fluid Phase Equilibria. 2(4): 297-309. https://doi.org/https://doi.org/10.1016/037 8-3812(79)80015-1.

Su M, Sun H, Zhao Y, Lu A, Cao X, Wang J. 2016. Degradation Kinetics and Mechanism of a $\& \# x 3 b 2$;-Lactam Antibiotic Intermediate, 6-Aminopenicillanic Acid, in a New Integrated Production Process. Journal of Pharmaceutical Sciences. 105(1): 139146.

https://doi.org/10.1016/j.xphs.2015.11.026

Szewczuk A, Ziomek E, Mordarski M, Siewiński M, Wieczorek J. 2018. Properties of penicillin amidase immobilized by copolymerization with acrylamide. Biotechnology and Bioengineering. 21(9): 1543-1552. https://doi.org/10.1002/bit.260210904.

Warburton D, Dunnill P, Lilly MD. 2018. Conversion of benzylpenicillin to 6aminopenicillanic acid in a batch reactor and continuous feed stirred tank reactor using immobilized penicillin amidase. Biotechnology and Bioengineering. 15(1): 13-25. https://doi.org/10.1002/bit.260150103.

Wei T, Wang C, Du S, Wu S, Li J, Gong J. 2015. Measurement and correlation of the solubility of penicillin $\mathrm{V}$ potassium in ethanol + water and 1-butyl alcohol + water systems. Journal of Chemical and Engineering Data. 60(1): 112-117. https://doi.org/10.1021/je5008422. 